\title{
FIRE LOSSES IN THE SLOVAK REPUBLIC - THEIR CLASSIFICATION AND QUANTIFICATION
}

The paper deals with approaches to fire loss classification and quantification. Direct and indirect loss, total loss per fire and the relation of direct and indirect loss to the gross domestic product (GDP) are calculated. Furthermore, the Statgraphics Centurion XV package is used to express: total loss prediction for selected probabilities and probabilities for selected total fire loss values. The results are discussed and conclusions drawn in form of recommendations for the Fire \& Rescue Services management in the Slovak Republic.

Keywords: Fire, losses, modelling, probability, distribution.

\section{Introduction}

This paper deals with the topic of fire loss classification and quantification. An analysis was carried out, using the available data which represent direct fire losses in the Slovak Republic. Direct loss was also supplemented by a quantitative expression of indirect loss. The aim of the paper is, based on statistical analysis, to offer managerial information on the probability of total loss in $€$, as well as the associated probabilities of loss occurrence. The outcomes of the analysis are then transformed into a set of recommendations for the Fire \& Rescue Service management.

Loss may be analysed from the following points of view:

- trend,

- occurrence probability,

- interdependencies with other statistical descriptors and benchmark comparison (including international comparison).

The results of these analyses should have a positive impact on the realisation of the management process in the Fire \& Rescue Service, as well as on the structure and process of statistical analysis (internal and external communication of processes and results).

\section{Analysis}

There is a number of approaches to incident loss classification; by an incident we understand, for the purposes of this paper, an event, the consequences of which lead to loss and potential system dysfunction (for more also see [1]).

\footnotetext{
* ' 'Jozef Klucka, ${ }^{2}$ Vladimir Mozer, ${ }^{1}$ Jan Dvorsky

${ }^{1}$ Department of Crisis Management, University of Zilina, Slovakia

${ }^{2}$ Department of Rescue Services, University of Zilina, Slovakia

E-mail: Jozef.Klucka@fbi.uniza.sk
}

Losses caused by emergencies are classified also [1] - Fig. 1.

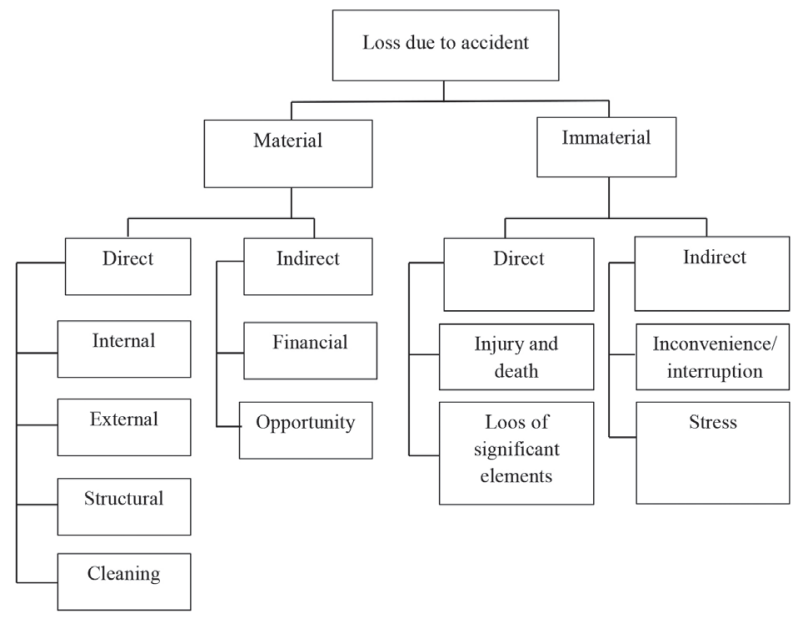

Fig. 1 Emergency-caused losses classification (for more also see [1])

From a fire-safety point of view Ramachandran [2] recognizes five levels in the management hierarchy, each having a different and specific view of topic of costs/losses and benefits. They are as follows: building owners, fire and rescue service, local authorities, government authorities, insurers and fire protection equipment manufacturers. Costs, such as installation of fire protection equipment, insurance premiums are real costs, however, the costs/losses associated with fire consequences are uncertain. Their height is tied to the probability of fire occurrence and the probable fire loss. The reduction of costs resulting from applied preventive measures is considered a benefit in this regard. 
Another view of costs results from their categorisation into direct - losses caused on the building and equipment due to a fire, and indirect - e.g. loss of production impacting profit, loss of customers, markets etc.

The direct loss on the building is expressed through an estimation of the expected replacement cost of the property damaged (for more also see [2]).

There is a number of approaches for fire loss quantification and they are organisation-specific. The insurance industry uses the following indicators (for more also see [3]):

Estimated maximum loss (EML): Usually expressed as percentage of value of unit under consideration. The fraction is likely to be charged in a serious conflagration.

Maximum possible loss: Financial loss that would occur under catastrophic or extremely unfavourable conditions (Failure of two or more protective systems - active and passive).

Maximum probable loss: Maximum financial loss under normal conditions, for example one protective system failing.

Normal loss expectancy: Financial loss under average operating conditions - all protective systems functional.

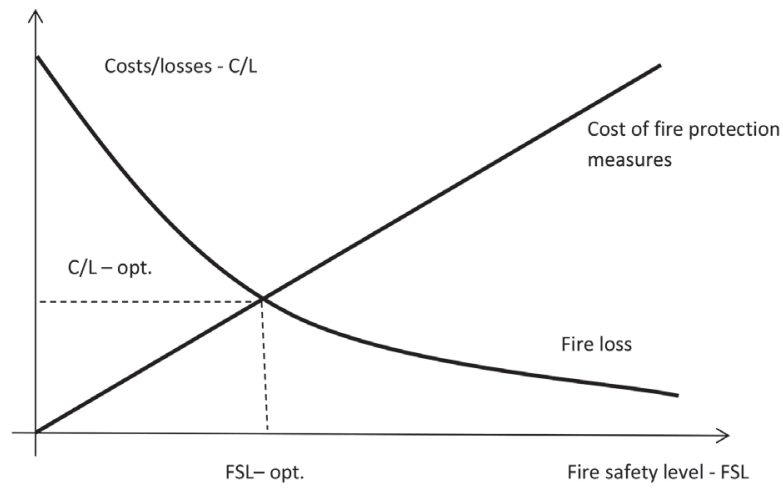

Fig. 2 Expression of optimisation conflict - fire losses vs fire safety level
Figure 2 illustrates the relationship between fire losses and the cost of fire protection measures. It is obvious, that for a given curve of costs and losses the (FLS - optimum C/L) point represent an optimum level - i.e. for the given level of costs, the losses are at their minimum value.

The extent of economic consequences of an accident is determined by the following elements:

- economic consequences are divided into direct and indirect,

- life loss and injuries represent specific forms of loss which are, although difficult, quantifiable

- economic consequences of an accident are driven by system's resilience,

- the ratio of direct and indirect loss is inconsistent among the sources (for more also see [1]), states that the indirect loss represent $25-40 \%$ of direct loss,

- there is only a limited theoretic methodology basis and statistical data required for incident consequence quantification.

The current methodology of Slovak Fire \& Rescue Service (FRS) recognizes only direct losses. They are recorded in accordance with internal guidelines of FRS (for more also see [4], [5] and [6]).

\section{Results}

The analysis included the following steps:

- total direct loss calculated from statistic report data was adjusted for inflation; direct loss was also used as the basis for the calculation of indirect loss for the analysed statistical set (see Table 1),

- based on the above total adjusted direct and indirect loss, direct and indirect loss per fire was calculated (see Table 2),

Direct and indirect loss in SR in 2003 - 2012

Table 1

\begin{tabular}{|l|c|c|c|c|c|c|c|}
\hline Year & Inflation (\%) & $\begin{array}{c}\text { Direct losses-DL } \\
(€)\end{array}$ & $\begin{array}{c}\text { Direct losses with } \\
\text { inflation }(€)\end{array}$ & $\begin{array}{c}\text { Indirect losses } \\
\text { IDL }(€)\end{array}$ & $\begin{array}{c}\text { Total losses TL } \\
(€)\end{array}$ & TL - $(€)$ & Growth coef. TL \\
\hline $\mathbf{2 0 0 3}$ & 8.5 & 18734874.0 & 20327338.3 & 6726573.0 & 27053911.3 & 8319037.3 & - \\
\hline $\mathbf{2 0 0 4}$ & 7.5 & 19539670.0 & 21005145.3 & 7006951.3 & 28012096.6 & 8472426.6 & 1.0 \\
\hline $\mathbf{2 0 0 5}$ & 2.7 & 27003084.0 & 27732167.3 & 9902582.3 & 37634749.6 & 10631665.6 & 1.3 \\
\hline $\mathbf{2 0 0 6}$ & 4.5 & 27121208.0 & 28341662.4 & 10174267.2 & 38515929.6 & 11394721.6 & 1.0 \\
\hline $\mathbf{2 0 0 7}$ & 2.8 & 46921954.0 & 48235768.7 & 19725511.6 & 67961280.3 & 21039326.3 & 1.8 \\
\hline $\mathbf{2 0 0 8}$ & 4.6 & 43493564.0 & 45494267.9 & 18339592.7 & 63833860.6 & 20340296.6 & 0.9 \\
\hline $\mathbf{2 0 0 9}$ & 1.6 & 38761305.0 & 39381485.9 & 15324004.8 & 54705490.7 & 15944185.7 & 0.9 \\
\hline $\mathbf{2 0 1 0}$ & 1.0 & 69148435.0 & 69839919.4 & 31271071.3 & 101110990.7 & 31962555.7 & 1.8 \\
\hline $\mathbf{2 0 1 1}$ & 3.9 & 33561130.0 & 34870014.1 & 13170022.3 & 48040036.4 & 14478906.4 & 0.5 \\
\hline $\mathbf{2 0 1 2}$ & 3.6 & 41394490.0 & 42884691.6 & 17039230.2 & 59923921.9 & 18529431.9 & 1.2 \\
\hline
\end{tabular}

Where:

$T L=D L_{\text {inf }}+I D L$ and $I D=c \times\left(D L_{\text {inf }}\right)^{b}$

where $c=0.015 ; b=1.245$ (due to missing data, calculation method form [2] was adopted). 
- subsequently, the total adjusted direct and indirect loss was recalculated as a percentage ratio of GDP (see Table 3), and the results were compared with selected European countries (see Table 4 and Table 5),

- finally, the adjusted direct and indirect loss was fitted to an appropriate statistical distribution (see Table 7 and Table 8); these values were then analysed for a relationship between probability and total loss value (variably for each given probability of total loss occurrence and the given amount of total loss) (see Table 9 and Table 10).

Having calculated the direct and indirect losses, their values were divided by the number of fires which had occurred in SR during the monitored period. The outcomes are as follows:

- the average value of direct loss per fire adjusted for inflation is $3200 €$ and the average indirect loss per fire is $1263 €$,
- the total loss per fire adjusted for inflation in the monitored period in the range of $1781-10264 €$; statistically, year 2010 is interesting due to the significant decrease of the number of fires, compared to preceding period, however, fire loss was extremely high; only a more detailed analysis of individual fires would provide explanation,

- by analysing the total loss per fire, it is possible to state that the development of its value has a significant variability; particularly the period of 2008 - 2012 would require further attention.

The further area of analysis was a comparison of direct and indirect loss in relation to GDP in the monitored period. The obtained results were compared with the published ones (see Table 3).

Direct and indirect loss per fire in SR during the period of 2003 - 2012

Table 2

\begin{tabular}{|c|c|c|c|c|c|c|c|}
\hline Year & Sum of fires & Direct losses & /fire $(€)$ & $\begin{array}{c}\text { Indirect losses } \\
\text { IDL }(€)\end{array}$ & IDL/fire $(€)$ & TL/fire $(€)$ & $\begin{array}{c}\text { Growth coef. TL/ } \\
\text { fire }\end{array}$ \\
\hline $\mathbf{2 0 0 3}$ & 15189.0 & 20327338.3 & 1338.3 & 6726573.0 & 442.9 & 1781.2 & - \\
\hline $\mathbf{2 0 0 4}$ & 10118.0 & 21005145.3 & 2076.0 & 7006951.3 & 692.5 & 2768.5 & 1.6 \\
\hline $\mathbf{2 0 0 5}$ & 11294.0 & 27732167.3 & 2455.5 & 9902582.3 & 876.8 & 3332.3 & 1.2 \\
\hline $\mathbf{2 0 0 6}$ & 10260.0 & 28341662.4 & 2762.3 & 10174267.2 & 991.6 & 3754.0 & 1.1 \\
\hline $\mathbf{2 0 0 7}$ & 14366.0 & 48235768.7 & 3357.6 & 19725511.6 & 1373.1 & 4730.7 & 1.3 \\
\hline $\mathbf{2 0 0 8}$ & 11045.0 & 45494267.9 & 4119.0 & 18339592.7 & 1660.4 & 5779.4 & 1.2 \\
\hline $\mathbf{2 0 0 9}$ & 11991.0 & 39381485.9 & 3284.3 & 15324004.8 & 1278.0 & 4562.2 & 0.8 \\
\hline $\mathbf{2 0 1 0}$ & 9851.0 & 69839919.4 & 7089.6 & 31271071.3 & 3174.4 & 10264.0 & 2.2 \\
\hline $\mathbf{2 0 1 1}$ & 13677.0 & 34870014.1 & 2549.5 & 13170022.3 & 962.9 & 3512.5 & 0.3 \\
\hline $\mathbf{2 0 1 2}$ & 14413.0 & 42884691.6 & 2975.4 & 17039230.2 & 1182.2 & 4157.6 & 1.2 \\
\hline
\end{tabular}

Relation of direct and indirect loss to GDP in monitored loss

\begin{tabular}{|l|c|c|c|c|c|c|}
\hline Year & GDP (mil. $€$ ) & $\begin{array}{c}\text { Direct losses with } \\
\text { inflation- }(€)\end{array}$ & $\begin{array}{c}\text { Indirect losses -IDL } \\
(€)\end{array}$ & /GDP (\%) & IDL/GDP (\%) & IDL/ \\
\hline $\mathbf{2 0 0 3}$ & 40612.00 & 20327338.29 & 6726572.98 & $0.050 \%$ & $0.017 \%$ & 0.331 \\
\hline $\mathbf{2 0 0 4}$ & 45161.40 & 21005145.25 & 7006951.32 & $0.047 \%$ & $0.016 \%$ & 0.334 \\
\hline $\mathbf{2 0 0 5}$ & 49314.20 & 27732167.27 & 9902582.34 & $0.056 \%$ & $0.020 \%$ & 0.357 \\
\hline $\mathbf{2 0 0 6}$ & 55001.60 & 28341662.36 & 10174267.2 & $0.052 \%$ & $0.018 \%$ & 0.359 \\
\hline $\mathbf{2 0 0 7}$ & 61449.70 & 48235768.71 & 19725511.6 & $0.078 \%$ & $0.032 \%$ & 0.409 \\
\hline $\mathbf{2 0 0 8}$ & 66932.30 & 45494267.94 & 18339592.6 & $0.068 \%$ & $0.027 \%$ & 0.403 \\
\hline $\mathbf{2 0 0 9}$ & 62895.50 & 39381485.88 & 15324004.8 & $0.063 \%$ & $0.024 \%$ & 0.389 \\
\hline $\mathbf{2 0 1 0}$ & 65887.40 & 69839919.35 & 31271071.3 & $0.106 \%$ & $0.047 \%$ & 0.448 \\
\hline $\mathbf{2 0 1 1}$ & 69058.20 & 34870014.07 & 13170022.3 & $0.050 \%$ & $0.019 \%$ & 0.378 \\
\hline $\mathbf{2 0 1 2}$ & 71463.00 & 42884691.64 & 17039230.2 & $0.060 \%$ & $0.024 \%$ & 0.397 \\
\hline
\end{tabular}


Direct and indirect loss in selected EU countries [2]

Table 4

\begin{tabular}{|c|c|c|}
\hline Country & Direct losses* $^{*}$ (\%) & Indirect losses* (\%) $^{*}$ \\
\hline Austria & $0.21(79-80)$ & 0.029 \\
\hline Belgium & $0.4(88-89)$ & N.A.* $^{* *}$ \\
\hline Denmark & 0.26 & 0.034 \\
\hline Finland & $0.17(88-89)$ & 0.021 \\
\hline France & 0.23 & 0.037 \\
\hline Germany & 0.2 & 0.037 \\
\hline Hungary & $0.12(86-88)$ & 0.028 \\
\hline Netherlands & 0.19 & 0.03 \\
\hline Norway & 0.24 & 0.005 \\
\hline Spain & $0.12(84)$ & N.A. \\
\hline Sweden & 0.25 & 0.009 \\
\hline Switzerland & $0.23(89))$ & 0.095 \\
\hline UK & 0.19 & 0.019 \\
\hline
\end{tabular}

*Average percentage of GDP

Direct and indirect loss in relation to GDP in selected EU countries [2]

Table 5

\begin{tabular}{|c|c|c|c|}
\hline Country & $\begin{array}{c}\text { Indirect } \\
\text { losses -ID } \\
(\% G D P)\end{array}$ & $\begin{array}{c}\text { Direct losses - } \\
\text { DL (\%GDP) }\end{array}$ & Ratio IDL/DL \\
\hline Norway & $0.005(58-60)$ & 0.24 & 0.021 \\
\hline Sweden & 0.009 & 0.25 & 0.036 \\
\hline The Netherlands & $0.030(87-88)$ & $0.19(87-88)$ & 0.158 \\
\hline Austria & $0.029(79-80)$ & $0.21(79-80)$ & 0.138 \\
\hline Germany & $0.037(87-89)$ & $0.20(89-90)$ & 0.185 \\
\hline Denmark & 0.034 & 0.26 & 0.131 \\
\hline Finland & $0.021(88-89)$ & $0.17(88-89)$ & 0.124 \\
\hline UK & 0.019 & 0.19 & 0.1 \\
\hline France & $0.037(80-81)$ & $0.23(81-82)$ & 0.161 \\
\hline Switzerland & $0.095(89)$ & $0.23(89)$ & 0.413 \\
\hline
\end{tabular}

${ }^{* *}$ N.A. - estimate not available

The following is evident from Table 4 and Table 5 (for more also see [7] and [8]):

- the ratio of direct loss to GDP is significantly lower than in other EU countries,
- the ratio of indirect loss to GDP in selected EU countries is in agreement with values (see Table 4 and Table 5),

- the ratio of indirect to direct loss is significantly higher in SR than in other EU countries; only a more in-depth analysis would provide reasons explaining this fact; it was not possible at the moment of writing this paper due to limited data availability.

The results of the above are determined by the following factors:

- from the available data, we presume that direct loss is not adjusted for inflation,

- the value of direct and indirect loss is determined by limited data; the presumed fact of different indirect loss for various building groups is simplified (see Table 5).

Statistical modelling of total fire loss comprised a number of stages, in which a number of distributions and calculation methods were tested and the most appropriate selected (for more also see [9] and [10]) The calculations were carried out in the STATGRAPHICS CENTURION XV package, due to the computational demands (for more also see [11], [12] and [13]). The basic selective characteristics (see Table 6) indicate that the selected group is characterised by a continuous probabilistic distribution due to a high coefficient of variation $-42.32 \%$.

Basic statistical characteristics of fire loss for the period of 2003 - 2012

Table 6

\begin{tabular}{|l|c|}
\hline Average & $5.26792 \mathrm{x}$ \\
\hline Standard deviation & $2.22954 \mathrm{x}$ \\
\hline Coefficient of variation & $42.323 \%$ \\
\hline Kurtosis & 1.01213 \\
\hline Skewness & 1.37392 \\
\hline
\end{tabular}

The estimated distribution parameters using the maximum likelihood method (see Table 7)

Parameter estimation for selected probabilistic distributions Table 7

\begin{tabular}{|c|c|c|c|c|}
\hline $\begin{array}{c}\text { Pareto } \\
\text { distribution }\end{array}$ & $\begin{array}{c}\text { Gamma } \\
\text { distribution }\end{array}$ & $\begin{array}{c}\text { Lognormal } \\
\text { distribution }\end{array}$ & $\begin{array}{c}\text { Weibull } \\
\text { distribution }\end{array}$ & $\begin{array}{c}\text { Normal } \\
\text { distribution }\end{array}$ \\
\hline$\alpha=0.05649$ & $\alpha=6.61954$ & $\mu=53131800$ & $\delta=2.64796$ & $\mu=52679200$ \\
\hline $\mathrm{c}=22587800$ & $\beta=1.25663 \mathrm{x}$ & $=23014300$ & $\mathrm{c}=59407600$ & $=22295400$ \\
\hline
\end{tabular}

\begin{tabular}{|c|c|c|c|c|c|}
\hline & Pareto distribution & Gamma distribution & Normal distribution & Weibull distribution & Lognormal distribution \\
\hline DPLUS & 0.17524 & 0.13652 & 0.11514 & 0.13981 & 0.14653 \\
\hline DMINUS & 0.00163 & 0.08991 & 0.10939 & 0.11716 & 0.12520 \\
\hline DN & 0.10163 & 0.13652 & 0.11514 & 0.13981 & 0.14653 \\
\hline P-value & 0.94138 & 0.99225 & 0.99937 & 0.98970 & 0.98280 \\
\hline
\end{tabular}


The tests were carried out on the $5 \%$ significance levels. With $95 \%$ level of confidence, the data fit the Lognormal distribution, since the P-value of Kolmogorov-Smirnov test is the highest for this distribution.

Having found that the total fire loss in SR for the period of 2003 - 2012 fits best to the Lognormal distribution, future extreme values for selected probabilities can be predicted.

Total fire loss prediction for selected probabilities

Table 9

\begin{tabular}{|c|c|}
\hline Probability of Total fire loss (\%) & Total fire loss (€) \\
\hline 20 & 69116700 \\
\hline 10 & 82948900 \\
\hline 5 & 96435700 \\
\hline 2 & 114255000 \\
\hline 1 & 127929000 \\
\hline
\end{tabular}

Probabilities for selected total fire loss

Table 10

\begin{tabular}{|c|c|}
\hline Total fire loss $(€)$ & Probability of Total fire loss (\%) \\
\hline 30000000 & 12.07 \\
\hline 50000000 & 52.43 \\
\hline 70000000 & 80.85 \\
\hline 90000000 & 93.03 \\
\hline 110000000 & 97.51 \\
\hline
\end{tabular}

The results from Table 9 and Table 10 can be interpreted as follows:

- with $10 \%$ probability, the expected loss in SR for the next year is $82948900 €$,

- the probability that the total loss will not exceed 70000000 $€$ is $80.81 \%$,

- analogically same interpretation applies to other values in Table 9 and Table 10.

Similar logic may be applied to other probabilities of total fire loss.

The analysis of the results yields the following outcomes:

- the average value of total direct loss in the monitored period is $36568000 €$; the average value of adjusted total direct loss is $37811000 €$; on average, inflation caused a $4 \%$ increase of direct loss,

- the increase of total loss, when compared to the direct loss for the given year, is approximately $44 \%$,

- the average difference of the total and adjusted direct loss is 16 mil. $€$ and the median of this item is 14.5 mil. $€$,
- the standard deviation value of the difference of total and direct loss is 7.2 mil. $€$, which suggests a significant variability of the analysed items,

- the average value of indirect loss is $14868000 €$; the median of this item $13170000 €$,

- the growth coefficient of total lost has a significant variance; the periods of growth and decrease alternate, with extremes in 2003 - 2004 (4\% increase) and years 2010 - 2011 (137\% growth).

4. Conclusion

The analysis of fire risk is carried out with the aim of risk reduction in decision making which deals with fire source identification, determination of the probability of a fire starting and consequence quantification. The process of loss analysis is also part of the risk management process. Knowing the probable consequences and their quantification allows to take appropriate measures as part of risk management, which help the organisation (FRS) decrease the risk to an acceptable level. In other words, the realised measures decrease the level of risk from unacceptable to acceptable.

From the presented results it is possible draw the following application conclusions for FRS:

- formulate a methodology for direct fire loss calculation and decide on the way of inflation integration,

- extend the current methodology for indirect fire loss,

- compare direct and indirect loss as part of analyses and quantify loss per fire,

- categorise fires by sectors/industries, and based on these extend the analysis of direct and indirect fire loss for the individual categories,

- carry out a trend analysis for each sector/industry development of direct an indirect loss in time,

- carry out an international comparison of the direct loss/GDP, indirect loss/GDP, and indirect and direct loss ratios,

- extend loss quantification for life loss and injury factors,

- analyse the methods currently used by the insurance industry for quantification (for more also see [3])

The above proposed measures have an ambition to include the results of statistical analyses into the FRS management more effectively.

\section{Acknowledgements}

This work was supported by the Slovak Research and Development Agency under the contract No APVV-0727-12. 


\section{References}

[1] Critical Infrastructure Resilience Strategy. Australian government, Canberra, 2010, (information on: www.ag.gov.au/cca)

[2] RAMACHANDRAN, G.: Economics of FireP. Published by E \& FN Spon, 1998, ISBN 0-203-78436-7, p. 247.

[3] RASBASH, D. J., RAMACHANDRAN, G., KANDOLA, B., WATTS, J. M., LAW, M.: Evaluation of Fire Safety. Wiley, 2004, p. 479, ISBN 0-471-49382-1

[4] Collection Instructions Presidium Fire and Rescue Service, No. 25, 2005 Ministry of Interior of the Slovak Republic.

[5] BETAKOVA, J., LORKO, M., DVORSKY J.: The Impact of the Potential Risks of the Implementation of Instruments for Environmental Area Management on the Development of Urban Settlement, Environmental impact II, Ancona, 2014, ISBN 978184564762-9, ISSN 17433541, pp. 91-101.

[6] BUTTON,K.: Transport Economics, Edward Elgar, 2010, p. 511

[7] CONTE, A. P. E. (ed.): Fire Protection Handbook, vol. I., NFTA, Quincy, 2008, ISBN-13:978-0-87765-758-3, p. 1584.

[8] DVORSKY, J., KLUCKA, J.: Modelling of the Amount of Economic Losses Causes by Fires in the Region of Zilina, Fire Protection 2014, Ostrava, ISBN 978-80-7385-148-4, pp. 48-51.

[9] Keeping the Country Running: Natural Hazards and Infrastructure, Cabinet Office, London, 2011 (information on: www. cabinetoffice.gov.uk/ukresilience)

[10] KELISEK, A., KLUCKA, J., ONDRUSEK, M., STRELCOVA, S.: Economic Security - A Principal Component of Multilevel Security Concept in Global Economy. Communications - Scientific Letters of the University of Zilina, 2011, ISSN 1335-4205, pp. 44-48.

[11] KLUCKA, J., MOZER, V., PANAKOVA, J.: Development of Fires in Different Categories of Buildings for the Period 1993 - 2012 , The conference of Rescue Services, Proc. of intern. scientific conferences, Zilina, ISBN 978-80-554-0894-1, pp. 91-110.

[12] PANAKOVA, J., KLUCKA, J., MOZER, V.: Model for Evaluation of Fire Protection Measures Economic Efficiency. Fire protection 2014, Ostrava, ISBN 978-80-7385-148-4, ISSN 1803-1803 pp. 264-266.

[13] STATGRAPHICS: Software Statgraphics Centurion XV. 2014. [online]. [cit. 25 March 2014]. Available: http://www.statgraphics. com/support/download_center.aspx. 